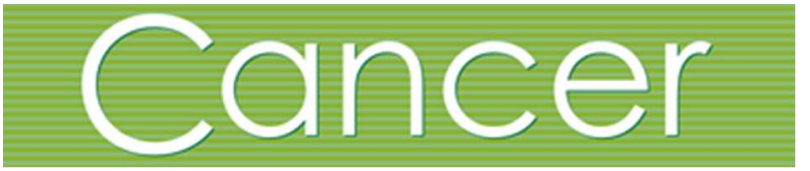

\title{
Long-term follow-up of patients with acute myeloid leukemia surviving and relapse-free for at least 2 years after autologous stem cell transplantation: a report from the Acute Leukemia Working Party of the European Group for Blood and Marrow Transplantation
}

\begin{tabular}{|c|c|}
\hline Journal: & Cancer \\
\hline Manuscript ID & CNCR-16-0090.R1 \\
\hline Wiley - Manuscript type: & Original Article \\
\hline Date Submitted by the Author: & 14-Feb-2016 \\
\hline Complete List of Authors: & $\begin{array}{l}\text { Czerw, Tomasz; Maria Sklodowska-Curie Memorial Cancer Centre and } \\
\text { Institute of Oncology, Department of Bone Marrow Transplantation and } \\
\text { Oncohematology } \\
\text { Labopin, Myriam; Hospital Saint Antoine, Dept. Hematology } \\
\text { Gorin, Norbert-Claude; Hopital Saint-Antoine APHP Paris, Clinical } \\
\text { Hematology and Cellular Therapy Department, The Acute Leukemia } \\
\text { Working Party of the EBMT office; INSERM UMRs 938; Pierre and Marie } \\
\text { Curie University (UPMC, Paris VI) } \\
\text { Giebel, Sebastian; Maria Sklodowska-Curie Memorial Cancer Center and } \\
\text { Institute of Oncology, Gliwice Branch, } \\
\text { Blaise, Didier; Institut Paoli Calmettes, Haematology } \\
\text { Meloni, Giovanna; Azienda Policlinico Umberto I, Dipartimento di } \\
\text { Ematologia } \\
\text { Pigneux, Arnaud; CHU, } \\
\text { Bosi, Alberto; Azienda Ospedaliero Universitaria "Careggi", Hematology } \\
\text { Veelken, Joan; BMT Centre Leiden, Leiden University Hospital } \\
\text { Ferrara, Felicetto; "A.Cardarelli" Hospital, Department of Hematology } \\
\text { Schaap, Nicolaas; Radboud University Nijmegen Medical Center, } \\
\text { Hematology } \\
\text { Lemoli, Roberto; Bologna University, S.Orsola-Malpighi Hospital Institute of } \\
\text { Hematology \& Medical Oncology L \& A Seragnoli; Department of Internal } \\
\text { Medicine (DiMI), University of Genoa } \\
\text { Cornelissen, Jan; Erasmus MC, Daniel den Hoed Oncology Clinic, } \\
\text { Hematology } \\
\text { Beohou, Eric; INSERM UMRs 938 } \\
\text { Nagler, Arnon; Sheba Medical Center, } \\
\text { Mohty, Mohamad; Hospital Saint-Antoine, APHP, }\end{array}$ \\
\hline Keywords: & $\begin{array}{l}\text { acute myeloid leukemia, stem cell transplantation, autologous } \\
\text { transplantation, recurrence, risk factors, follow-up }\end{array}$ \\
\hline
\end{tabular}




\section{Page 1 of 28}

Cancer

1

2

3

4

5

6

7

8

9

10

11

12

13

14

15

16

17

18

19

20

21

22

23

24

25

26

27

28

29

30

31

32

33

34

35

36

37

38

39

40

41

42

43

44

45

46

47

48

49

50

51

52

53

54

55

56

57

58

59

60

SCHOLARONE ${ }^{m}$

Manuscripts 


\section{TITLE PAGE}

Long-term follow-up of patients with acute myeloid leukemia surviving and relapsefree for at least 2 years after autologous stem cell transplantation: a report from the Acute Leukemia Working Party of the European Group for Blood and Marrow Transplantation

Running title: Long-term follow-up of auto-SCT for AML

Tomasz Czerw, $\mathrm{MD}^{1}$; Myriam Labopin, $\mathrm{MD}^{2,3,4}$; Norbert-Claude Gorin, $\mathrm{MD}^{2,3,4}$; Sebastian Giebel, MD ${ }^{1}$; Didier Blaise, $\mathrm{MD}^{5}$; Giovanna Meloni, MD ${ }^{6}$; Arnaud Pigneux, $\mathrm{MD}^{7}$; Alberto Bosi, $\mathrm{MD}^{8}$; Joan H. Veelken, $\mathrm{MD}^{9}$; Felicetto Ferrara, MD ${ }^{10}$; Nicolaas Schaap, $\mathrm{MD}^{11}$; Roberto M. Lemoli, MD ${ }^{12}$; Jan J. Cornelissen, $\mathrm{MD}^{13}$; Eric Beohou, $\mathrm{MD}^{3}$; Arnon Nagler, $\mathrm{MD}^{14,2 *}$; and Mohamad Mohty, $\mathrm{MD}^{2,3,4 *}$

* These authors contributed equally to this work

${ }^{1}$ Department of Bone Marrow Transplantation and Oncohematology, Maria SklodowskaCurie Memorial Cancer Centre and Institute of Oncology, Gliwice Branch, Gliwice, Poland

${ }^{2}$ Clinical Hematology and Cellular Therapy Department, The Acute Leukemia Working Party of the EBMT office, Hopital Saint-Antoine APHP Paris, France

${ }^{3}$ INSERM UMRs 938, Paris, France

${ }^{4}$ Pierre and Marie Curie University (UPMC, Paris VI), Paris, France 
5 Department of Transplantation and Cellular Therapy, Paoli Calmettes Institute, Marseille, France

${ }^{6}$ Department of Cellular Biotechnology and Hematology, 'LaSapienza` University, Rome, Italy

${ }^{7}$ Department of Hematology and Cellular Therapy, University Hospital of Bordeaux, France

${ }^{8}$ BMT Unit Department of Hematology, di Careggi Hospital, Florence, Italy

${ }^{9}$ BMT Centre Leiden, Leiden University Hospital, Leiden, The Netherlands

${ }^{10}$ Cardarelli Hospital, Napoli, Italy

${ }^{11}$ Department of Hematology, Radboud University - Nijmegen Medical Centre, Nijmegen, The Netherlands

${ }^{12}$ Bologna University, S.Orsola-Malpighi Hospital Institute of Hematology \& Medical Oncology L \& A Seragnoli, Bologna, Italy; present address: Chair of Hematology, Department of Internal Medicine (DiMI), University of Genoa, Genoa, Italy

${ }^{13}$ Department of Hematology, Erasmus University medical center Cancer Institute, Rotterdam, The Netherlands

${ }^{14}$ Hematology and Bone Marrow Transplantation, Chaim Sheba Medical Center, Tel Hashomer, Israel 
Corresponding author: Tomasz Czerw, MD, Department of Bone Marrow Transplantation and Oncohematology, Maria Sklodowska-Curie Memorial Cancer Centre and Institute of Oncology, Gliwice Branch; Wybrzeze Armii Krajowej 15 Street, 44-101 Gliwice, Poland; phone +48 $32 \quad 278 \quad 85$ 23, fax +48 $32 \quad 27891$ 49, e-mail: tomcmed@gmail.com

Text pages: 20; Tables: 3; Figures: 4

The work had no specific funding.

The authors declare no conflict of interest.

The contributions of all authors: TC was the primary investigator for this study. TC, ML, N-CG, SG, AN and MM designed the study, the synopsis of which was approved by the Acute Leukemia Working Party of the EBMT. ML and EB did the statistical analysis. TC wrote the first draft of the manuscript. All other co-authors contributed data to the EBMT registry, read the manuscript and approved the final version.
Precis: Late relapses remain a major concern for long-term survivors of autologous stem cell transplantation for acute myeloid leukemia. This indicates the need for close minimal residual disease monitoring and additional leukemic control measures post transplantation.




\section{Abstract}

BACKGROUND: Leukemia relapse is a major cause of treatment failure after autologous stem cell transplantation (auto-SCT) for acute myeloid leukemia (AML). It usually occurs within the first two years after transplantation. The goal of this retrospective study was to assess the follow-up and characterize risk factors for outcome of patients who survived relapse-free after this period. METHODS: The analysis included 3567 adults (median age 45 years) with AML, autografted in first $(86 \%)$ or second (14\%) complete remission between 1990 and 2008. The stem cell source was bone marrow $(\mathrm{BM})(32 \%)$ or peripheral blood $(\mathrm{PB})(68 \%)$. The median follow-up was 6.9 years. RESULTS: At 5 and 10 years after transplantation, the probability of leukemia-free survival was $86 \%$ and $76 \%$, the relapse incidence, $11 \%$ and $16 \%$, and the non-relapse mortality, $3 \%$ and $8 \%$, respectively. The observed survival was decreased as compared to the expected survival of the general European population. In a multivariate analysis decreased probability of leukemia-free survival was demonstrated for PB-autoSCT, French-American-British subtypes M0, M6 or M7 and older age. The same factors were associated with increased risk of relapse. Non-relapse mortality was affected by older age.

CONCLUSIONS: Our analysis indicates that late relapses remain a major concern after auto-SCT for AML, indicating the need for close minimal residual disease monitoring and additional leukemic control measures post transplantation.

Keywords: acute myeloid leukemia, stem cell transplantation, autologous transplantation, recurrence, risk factors, follow-up 


\section{Introduction}

Autologous stem cell transplantation (auto-SCT) used as a part of post-remission therapy may offer an advantage in a subgroup of patients with acute myeloid leukemia (AML). It can be recommended as one of the treatment options for individuals with favorable- and intermediate-risk disease status based on cytogenetic and molecular stratification. ${ }^{1} \mathrm{~A}$ meta-analysis of nine randomized trials in adults demonstrated advantage of auto-SCT over additional conventional-dose chemotherapy in terms of reduced risk of relapse and improved leukemia-free survival (LFS). ${ }^{2}$ However, no significant effect was shown with respect to the overall survival (OS).$^{2-3}$ Hence, the role of auto-SCT for AML remains an issue of debate and requires further investigation. ${ }^{4-6}$

As compared to allogeneic SCT (allo-SCT), the major disadvantage of autotransplantation is leukemia relapse, which may be only in part counterbalanced by lower NRM..$^{7-9}$ The high relapse rate may be a consequence of graft contamination with leukemic blasts and the lack of graft-versus leukemia effect. Relapses occur mainly during the first 2 years after the procedure and, therefore, patients surviving relapse-free after this period are considered to have a good prognosis. ${ }^{2-6}$ However, their long-term outcome is rarely reported and the risk of late events is poorly characterized.

This issue appears important for full interpretation of results of clinical trials and could contribute to further evaluation of the role of auto-SCT in AML. Furthermore, it was previously shown, that early estimation of transplantation outcome may not be able to predict late failures. ${ }^{10}$ Thus, the goal of the current study was to evaluate for the first time long-term follow-up and characterize risk factors for outcome in a large population of 


\begin{abstract}
AML patients autografted between 1990 and 2008 who survived relapse-free for at least 2 years after autoSCT.
\end{abstract}

\title{
Subjects and methods
}

\section{Study design and data collection}

This study was a retrospective multicenter analysis. The design was approved by the Acute Leukemia Working Party of the European Group for Blood and Marrow Transplantation (EBMT) and followed registry studies guidelines. Since 1990, patients provide informed consent authorizing the use of their personal information for research purposes. The inclusion criteria were set as follows: 1) patients with AML in first (CR1) or second (CR2) complete remission treated with their first auto-SCT between January 1990 and December 2008, 2) age $\geq 18$ years, 3) bone marrow (BM) or peripheral blood (PB) used as a source of stem cells, 4) alive without relapse within the first 2 years after transplantation. Patients with secondary AML were excluded from the analysis.

\section{Patients and auto-SCT procedure}

Altogether, 3567 individuals met the selection criteria. Their median age was 45 years (range, 18-78), and 52\% of them were male. The diagnosis of AML was established according to the French-American-British (FAB) morphological classification and was distributed as follows: M0-2\%, M1-18\%, M2-28\%, M3-10\%, M4-24\%, M5-15\%, M62\%, M7-1\%. Cytogenetic data were available for 1,119 cases (31\%). Among those with known karyotype, $26 \%$ had favorable, $71 \%$ intermediate and 3\% unfavorable cytogenetic 
features according to established criteria. ${ }^{1}$ Molecular biology data were too limited to be included in the analysis. Auto-SCT was performed in CR1 $(n=3,087,86 \%)$ or CR2 $(n=480,14 \%)$. The stem cell source was BM $(n=1,153,32 \%)$ or PB $(n=2,414,68 \%)$ with a significant shift towards PB after the year 2000 (11\% before and $69 \%$ after). The conditioning regimen was based on chemotherapy in $78 \%$ and total body irradiation (TBI) in $22 \%$ of cases, and graft ex vivo purging was performed in $6 \%$ of cases. The median auto-SCT year was 2000 and the median follow-up was 6.9 years (range, 2.0-21.5). Detailed patient characteristics are summarized in (Table 1).

\section{Statistical analysis}

The outcome was assessed by estimating: 1) LFS, defined as survival with no evidence of relapse, 2) OS, 3) relapse incidence (RI), 4) NRM, defined as probability of death while in CR. Cumulative incidence functions were used to estimate RI and NRM in a competing risks setting. ${ }^{11}$ Probabilities of LFS and OS were calculated using the KaplanMeier estimate. ${ }^{12}$ The median follow-up and the outcome were estimated from the date of transplantation. Univariate analyses were done using the log rank test for LFS and OS and Gray's test for RI and NRM. Multivariate analyses were performed using Cox proportional-hazard model for LFS and OS, and Fine-Gray model for RI and NRM. ${ }^{13-14}$

Additional analysis was performed to compare the OS of the group of patients under study to the general European population. The expected survival computations were based on a set of tables containing one year death rates by age and gender for the European population published by the EUROSTAT organization. ${ }^{15}$ We used life tables from 1990 to 2012 and transformed death rates to have a daily hazard. ${ }^{16}$ The conditional 
estimate method was used to calculate the expected survival curves. This method assumes that each control is followed until death or censoring of its matched case. ${ }^{17}$ Statistical analyses were performed with SPSS 19 (SPSS Inc, Chicago, IL), and R 2.13.2 (R Development Core Team, Vienna, Austria) software packages.

\section{Results}

\section{Leukemia-free survival and overall survival}

The probability of LFS for patients who remained alive with no signs of AML recurrence at least 2 years after auto-SCT, calculated at 5 and 10 years after transplantation, was $86 \%$ (95\% confidence interval, 84-87\%) and 76\% (74-78), respectively (Figure 1).

In a univariate analysis (Table 2) the probability of LFS decreased with increasing age of patients at auto-SCT $(P<0.0001)$ (Figure 2). Factors which characterize the disease, like FAB classification and cytogenetics also affected LFS. Patients with M3 AML had the highest probability of LFS, as compared to those with FAB M1, M2, M4 or M5, and the latter fared better than those with M0, M6 or M7 $(P<0.0001)$. Adverse cytogenetic risk category, use of $\mathrm{PB}$ rather than $\mathrm{BM}$ as stem cell source and transplantations performed after year 2000 were correlated with decreased probability of LFS $(P=0.003, \quad P<0.0001$ and $P<0.001$, respectively). Graft purging procedures correlated with better LFS $(P=0.004)$.

The following variables were included in the multivariate analyses: patient age in 3 classes, disease status at transplantation, source of stem cells, graft purging, FAB classification in 3 classes and the use of TBI-based conditioning regimen. Only older age, 
PB as a source of stem cells and FAB subtypes M0, M6 or M7 were associated with decreased probability of LFS (Table 3).

As data on cytogenetics were unavailable for the majority of patients, this factor could not be included in a multivariate model. However, there was a strong association between the karyotype risk groups and FAB subtypes. Among FAB M1, M2, M4, or M5 subtypes, 169 patients (19\%) had favorable, 685 (77\%) had intermediate, and $41(5 \%)$ had high risk karyotype. Among the M0, M6, or M7 subtypes respective numbers were $1(2 \%), 53$ $(98 \%)$ and $0(p=0.001)$. No significant association could be observed between karyotype risk groups and the source of stem cells.

The same factors as for LFS were found to influence the OS (Tables 2 and 3). In addition, the use of TBI-based conditioning was associated with increased risk of mortality in a multivariate model (Table 3).

\section{Relapse incidence}

The cumulative RI at 5 and 10 years was $11 \%(10-12)$ and $16 \%(14-17)$, respectively (Figure 1). In a univariate analysis, the RI was affected by the same factors as in case of LFS, except for graft purging, which tended to correlate with reduced RI $(P=0.053)$ (Table 2). Use of PB rather than BM as stem cell source was associated with higher RI $(\mathrm{P}<0.0001)$ (Figure 3). In a multivariate model, increased risk of relapse was demonstrated for increasing patient age, PB grafts and adverse FAB subtypes (Table 3).

Non-relapse mortality 
The cumulative incidence of NRM at 5 and 10 years was 3\% (3-4) and 8\% (7-10), respectively (Figure 1). In a univariate analysis, the incidence of NMR was higher for male than for female patients $(P=0.002)$ and also for older patients $(P<0.0001)$ (Table 2$)$. In a multivariate model, increased risk of NRM was associated with increasing patient age (Table 3).

\section{Relative survival}

The observed overall study population survival was found to be decreased as compared to the expected survival of the general European population (Figure 4).

\section{Discussion}

According to results of large registry-based retrospective analyses, relapses affect approximately $45 \%$ of patients with AML treated with auto-SCT in CR. ${ }^{8,18-19}$ Most of these events occur early after transplantation, and it is believed that the risk of relapse after two years is marginal. ${ }^{2-6,18-19}$ Results from the present study clearly indicate that this assumption is incorrect, as the cumulative RI at 10 years reached $16 \%$, which represented the major cause of treatment failure among long-term survivors.

Our study was the largest so far focusing on this issue and included 3567 individuals. Two previous reports, both from North American institutions, described 315 and 159 patients, respectively. ${ }^{20-21}$ According to the analysis by Majhail et al., the RI after 10 years was lower compared to our observations, and equaled $6 \%$ for patients treated with auto-SCT in CR1 and $10 \%$ for those in CR2. ${ }^{20}$ It must be stressed, however, that those 
investigators included adolescents (age 10-19 years) and children (age below 10 years), who constituted $26 \%$ of the entire population, and that the median age of their group was 35 years compared to 45 years in our cohort. Furthermore, bone marrow was the predominant stem cell source in that study (72\%) and additionally purging of graft was performed in $44 \%$ of cases, which also markedly differs from our population. As those factors are recognized as predictors of relapse, results of the two studies are hardly comparable.

The findings from the Bone Marrow Transplant Survivor Study seem to agree better with ours. $^{21}$ According to that analysis, the cumulative mortality at 10 years was $17 \%$, with leukemia relapse being the leading cause of death. Interestingly, AML was associated with better outcome, compared to other indications for auto-SCT such as lymphomas or acute lymphoblastic leukemia.

Recurrent malignancy was also shown to contribute to the largest fraction of deaths in Martin et al.'s analysis of 5-year survivors after transplantation. ${ }^{22}$ However, that study's population was heterogeneous in terms of transplant type (auto- and allo-SCT) and diseases.

The observed survival of our study population was decreased as compared to the expected survival of the age- and gender-matched general European population. The leading cause of mortality was AML relapse (74\%). These results are in accordance with the above cited studies by Bhatia et al. and Martin at al. ${ }^{21,22}$

Patient age and FAB subtype were identified to influence the overall results in a multivariate analysis. Unfortunately, data for cytogenetics were missing for a significant proportion of patients, which was partially due to the fact that about $50 \%$ of our patients 
were diagnosed before the year 2000, when the availability of such tests was low. Nevertheless, the prognostic significance of cytogenetics was apparent in a univariate analysis and karyotype risk groups were strongly associated with FAB subtypes. As demonstrated in a series of prospective and retrospective investigations, the above three factors reflect the most important general predictors of outcome in AML, and are still important in the long term follow-up. ${ }^{1-6,9,18-19}$

In the present study, PB as a source of stem cells was associated with higher RI and inferior LFS, as compared to BM. The role of stem cell source was demonstrated in a previous EBMT studies by Gorin et al., in which patients' outcome was analyzed from the day of auto-SCT. The authors showed that the use of PB was associated with increased RI and decreased LFS. ${ }^{23-24}$ This could reflect a higher probability of PB grafts being contaminated with leukemia cells which, in turn, was found be an important predictor of relapse. $^{25-26}$

According to our observations, the type of conditioning regimen (TBI- vs. chemotherapybased) did not significantly affect neither LFS, RI nor NRM. However, when included in a multivariate model, the use of TBI was associated with slightly increased risk of the overall mortality, which is in line with findings published by some other groups. ${ }^{27-29}$

CR status at transplantation (1st or 2nd) did not influence outcomes when considering patients remaining in remission 2 years after the procedure. Higher RI and worse LFS rates seen after the year 2000 could be associated with the stem cell source used for transplantation. There was a significant shift towards PB after 2000, which constituted $69 \%$ compared to $11 \%$ before that year. 
In summary, our analysis indicates that late relapses remain a major concern after autoSCT for AML. The observed survival is decreased as compared to the expected survival of the general European population. This indicates the need for prolonged monitoring of the remission status in standard clinical practice. It may also suggest the indication for post transplant tumor control measures, such as maintenance chemotherapy with, for instance, hypomethylating agents, as presently tested post allogeneic transplantation. ${ }^{30,31}$ The potentially encouraging thing might be that, in such long-term survivors, toxicity from the auto-SCT preparative conditioning might have sufficiently resolved to make subsequent allogeneic transplant more likely feasible at a later time point in disease management. Several patient, disease and procedure-related factors influence the overall results. Future directions may include assessment of minimal residual disease at the time of stem cell collection as well as strategies to prevent relapse after the procedure. 
Acknowledgments: Mohamad Mohty thanks Prof. J.V. Melo (Adelaide, Australia) for critical reading of the manuscript. Mohamad Mohty also acknowledges the educational grants received from the "Association for Training, Education and Research in Hematology, Immunology and Transplantation" (ATERHIT). The Saint-Antoine hospital group is supported by several grants from the Clinical Research Program of the French National Cancer Institute (PHRC cancer) to Mohamad Mohty. 


\section{References}

1. Döhner H, Estey EH, Amadori S, et al.; European LeukemiaNet. Diagnosis and management of acute myeloid leukemia in adults: recommendations from an international expert panel, on behalf of the European LeukemiaNet. Blood. 2010;115(3):453-74.

2. Wang J, Ouyang J, Zhou R, Chen B, Yang Y. Autologous hematopoietic stem cell transplantation for acute myeloid leukemia in first complete remission: a metaanalysis of randomized trials. Acta Haematol. 2010;124(2):61-71.

3. Vellenga E, van Putten W, Ossenkoppele GJ, et al.; Dutch-Belgian Hemato-Oncology Cooperative Group (HOVON); Swiss Group for Clinical Cancer Research Collaborative Group (SAKK). Autologous peripheral blood stem cell transplantation for acute myeloid leukemia. Blood. 2011;118(23):6037-42.

4. Ossenkoppele GJ, Janssen JJ, Huijgens PC. Autologous Stem Cell Transplantation in elderly Acute Myeloid Leukemia. Mediterr J Hematol Infect Dis. 2013;5(1):e2013018.

5. Seshadri T, Keating A. Is there a role for autotransplants in AML in first remission? Biol Blood Marrow Transplant. 2009;15(1 Suppl):17-20.

6. Breems DA, Löwenberg B. Acute myeloid leukemia and the position of autologous stem cell transplantation. Semin Hematol. 2007;44(4):259-66.

7. Koreth J, Schlenk R, Kopecky KJ, et al. Allogeneic stem cell transplantation for acute myeloid leukemia in first complete remission: systematic review and meta-analysis of prospective clinical trials. JAMA. 2009;301(22):2349-61.

8. Keating A, DaSilva G, Pérez WS, et al. Autologous blood cell transplantation versus HLA-identical sibling transplantation for acute myeloid leukemia in first complete 
remission: a registry study from the Center for International Blood and Marrow Transplantation Research. Haematologica. 2013;98(2):185-92.

9. Burnett AK, Goldstone AH, Stevens RM, et al. Randomised comparison of addition of autologous bone-marrow transplantation to intensive chemotherapy for acute myeloid leukaemia in first remission: results of MRC AML 10 trial. UK Medical Research Council Adult and Children's Leukaemia Working Parties. Lancet. 1998;351(9104):700-8.

10. Shimoni A, Hardan I, Shem-Tov N, Yerushalmi R, Nagler A. Allogeneic hematopoietic stem-cell transplantation in AML and MDS using myeloablative versus reduced-intensity conditioning: long-term follow-up. Leukemia. 2010;24(5):1050-2.

11. Gooley TA, Leisenring W, Crowley JA, Storer BE. Estimation of failure probabilities in the presence of competing risks: New representations of old estimators. Stat Med. $1999 ; 18: 665-706$.

12. Kaplan EL, Meier P. Non parametric estimation from incomplete observations. J Am Stat Assoc. 1958;53:457-81.

13. Cox DR. Regression models and life tables. J R Stat Soc. 1972;34:187-202.

14. Fine JP, Gray RJ. A proportional hazards model for subdistribution of a competing risk. Journal of American Statistical Association. 1999;94:496-509.

15. European Commission - Eurostat - Data - Database: Population and social conditions - Demography and migration - Mortality. Available from: http://ec.europa.eu/eurostat/data/database?node_code=demo_mlifetable

16. Therneau T, Offord J. Expected survival based on hazard rates (update). Technical Report Number 63. Section of Biostatistics. Mayo Clinic 1999. 
17. MathSoft S-Plus 2000. Guide to statistics 2. Data analysis production division of MathSoft. Seattle,WA, 1999.

18. Czerw T, Labopin M, Gorin NC, et al. Use of G-CSF to hasten neutrophil recovery after auto-SCT for AML is not associated with increased relapse incidence: a report from the Acute Leukemia Working Party of the EBMT. Bone Marrow Transplant. 2014;49(7):950-4.

19. Nagler A, Labopin M, Gorin NC, et al. Intravenous busulfan for autologous stem cell transplantation in adult patients with acute myeloid leukemia: a survey of 952 patients on behalf of the Acute Leukemia Working Party of the European Group for Blood and Marrow Transplantation. Haematologica. 2014;99(8):1380-6.

20. Majhail NS, Bajorunaite R, Lazarus HM, et al. High probability of long-term survival in 2-year survivors of autologous hematopoietic cell transplantation for AML in first or second CR. Bone Marrow Transplant. 2011;46(3):385-92.

21. Bhatia S, Robison LL, Francisco L, et al. Late mortality in survivors of autologous hematopoietic-cell transplantation: report from the Bone Marrow Transplant Survivor Study. Blood. 2005;105(11):4215-22.

22. Martin PJ, Counts GW Jr, Appelbaum FR, et al. Life expectancy in patients surviving more than 5 years after hematopoietic cell transplantation. J Clin Oncol. 2010;28(6):1011-6.

23. Gorin NC, Labopin M, Blaise D, et al.; Acute Leukemia Working Party of the European Cooperative Group for Blood and Marrow Transplantation. Higher incidence of relapse with peripheral blood rather than marrow as a source of stem 
cells in adults with acute myelocytic leukemia autografted during the first remission. J Clin Oncol. 2009;27(24):3987-93.

24. Gorin NC, Labopin M, Reiffers J, et al.; Acute Leukemia Working Party, European Cooperative Group for Blood and Marrow Transplantation. Higher incidence of relapse in patients with acute myelocytic leukemia infused with higher doses of CD34+ cells from leukapheresis products autografted during the first remission. Blood. 2010;116(17):3157-62.

25. Plesa A, Elhamri M, Clapisson G, et al. Higher percentage of CD34(+)CD38(-) cells detected by multi-parameter flow cytometry from leukapheresis products predict unsustained complete remission in AML. Leuk Lymphoma. 2015;56(3):622-9.

26. Terwijn M, van Putten WL, Kelder A, et al. High prognostic impact of flow cytometric minimal residual disease detection in acute myeloid leukemia: data from the HOVON/SAKK AML 42A study. J Clin Oncol. 2013;31(31):3889-97.

27. Adès L, Guardiola P, Sociè G. Second malignancies after allogeneic hematopoietic stem cell transplantation: new insight and current problems. Blood Rev. 2002;16(2):135-46.

28. Socié G, Salooja N, Cohen A, et al.; Late Effects Working Party of the European Study Group for Blood and Marrow Transplantation. Nonmalignant late effects after allogeneic stem cell transplantation. Blood. 2003;101(9):3373-85.

29. Duell T, van Lint MT, Ljungman P, et al. Health and functional status of long-term survivors of bone marrow transplantation. EBMT Working Party on Late Effects and EULEP Study Group on Late Effects. European Group for Blood and Marrow Transplantation. Ann Intern Med. 1997;126(3):184-92. 
30. Tessoulin B, Delaunay J, Chevallier P, et al. Azacitidine salvage therapy for relapse of myeloid malignancies following allogeneic hematopoietic SCT. Bone Marrow Transplant. 2014;49(4):567-71.

31. Estey EH. Epigenetics in clinical practice: the examples of azacitidine and decitabine in myelodysplasia and acute myeloid leukemia. Leukemia. 2013;27(9):1803-12. 


\section{FIGURE LEGENDS}

Figure 1. Outcomes of patients with AML remaining relapse-free at least 2 years after auto-SCT

Abbreviations: LFS - leukemia-free survival; RI - relapse incidence; NRM - non-relapse mortality

Figure 2. Leukemia-free survival of patients with AML remaining relapse-free at least 2 years after auto-SCT according to age groups

Figure 3. Relapse incidence of patients with AML remaining relapse-free at least 2 years after auto-SCT according to the source of stem cells

Abbreviations: $\mathrm{BM}$ - bone marrow; $\mathrm{PB}$ - peripheral blood

Figure 4. Overall survival of patients with AML remaining relapse-free at least 2 years after auto-SCT, as compared to the expected survival of the general European population by age 


\section{Table 1. Patient characteristics}

\begin{tabular}{|c|c|}
\hline $\mathrm{N}$ & 3567 \\
\hline \multicolumn{2}{|l|}{ Gender } \\
\hline Female & $1842(51.7 \%)$ \\
\hline Male & $1725(48.2 \%)$ \\
\hline missing & $5(0.1 \%)$ \\
\hline Median patient age, range (years) & $45(18-78)$ \\
\hline$<50$ years & $2330(65.3 \%)$ \\
\hline 50-60 years & $922(25.9 \%)$ \\
\hline$>60$ years & $315(8.8 \%)$ \\
\hline \multicolumn{2}{|l|}{ Cytogenetic risk } \\
\hline Favorable & $291(8.2 \%)$ \\
\hline Intermediate & $782(21.9 \%)$ \\
\hline Unfavorable & $46(1.3 \%)$ \\
\hline Unknown & $2448(58.6 \%)$ \\
\hline \multicolumn{2}{|l|}{ FAB classification } \\
\hline M0 & $78(2.2 \%)$ \\
\hline M1 & $618(17.3 \%)$ \\
\hline M2 & $947(26.6 \%)$ \\
\hline M3 & $333(9.3 \%)$ \\
\hline M4 & $799(22.4 \%)$ \\
\hline M5 & $491(13.8 \%)$ \\
\hline M6 & $73(2.1 \%)$ \\
\hline M7 & $16(0.4 \%)$ \\
\hline Missing & $212(5.9 \%)$ \\
\hline Median year of transplantation, range & $2000(1990-2008)$ \\
\hline \multicolumn{2}{|l|}{ AML status at auto-SCT } \\
\hline CR1 & $3087(86.5 \%)$ \\
\hline $\mathrm{CR} 2$ & $480(13.5 \%)$ \\
\hline \multicolumn{2}{|l|}{ Source of stem cells } \\
\hline $\mathrm{BM}$ & $1153(32.3 \%)$ \\
\hline PB & $2414(67.7 \%)$ \\
\hline \multicolumn{2}{|l|}{ Graft purging } \\
\hline No & $2915(81.7 \%)$ \\
\hline Yes & $190(5.3 \%)$ \\
\hline Unknown & $462(13.0 \%)$ \\
\hline \multicolumn{2}{|l|}{ Type of conditioning } \\
\hline Chemotherapy-based & $2652(74.4 \%)$ \\
\hline TBI-based & $753(21.1 \%)$ \\
\hline Unknown & $162(4.5 \%)$ \\
\hline Median follow-up, range (years) & $6.9(2-21.5)$ \\
\hline
\end{tabular}

Abbreviations: FAB - French-American-British classification; AML - acute myeloid leukemia; auto-SCT autologous stem cell transplantation; CR1 - first complete remission; CR2 - second complete remission; BM bone marrow; PB - peripheral blood; TBI - total body irradiation 
Table 2. Univariate analysis of prognostic factors

\begin{tabular}{|c|c|c|c|c|c|}
\hline Factor & 10-year outcome & LFS $\%$ & RI \% & NRM \% & OS $\%$ \\
\hline Patient gender & $\begin{array}{l}\text { Male } \\
\text { Female } \\
\text { P-value }\end{array}$ & $\begin{array}{c}74(72-77) \\
77(75-80) \\
0.13\end{array}$ & $\begin{array}{c}16(14-18) \\
16(14-18) \\
0.74\end{array}$ & $\begin{array}{c}10(8-12) \\
6(5-8) \\
0.002\end{array}$ & $\begin{array}{c}78(75-80) \\
81(78-83) \\
0.14\end{array}$ \\
\hline Age at autoSCT & $\begin{array}{l}<50 \\
50-60 \\
\geq 60 \\
P \text {-value }\end{array}$ & $\begin{array}{c}82(80-84) \\
65(61-69) \\
53(45-62) \\
<0.0001\end{array}$ & $\begin{array}{c}12(11-14) \\
21(18-24) \\
29(23-36) \\
<0.0001\end{array}$ & $\begin{array}{c}5(3-8) \\
14(10-19) \\
18(13-23) \\
<0.0001 \\
\end{array}$ & $\begin{array}{c}86(84-87) \\
68(64-72) \\
57(48-65) \\
<0.0001\end{array}$ \\
\hline $\begin{array}{l}\text { Cytogenetic } \\
\text { classification }\end{array}$ & $\begin{array}{l}\text { Favorable } \\
\text { Intermediate } \\
\text { Poor } \\
\text { P-value (3 groups) } \\
\text { Missing cytogenetics } \\
\text { P-value (missing vs other) }\end{array}$ & $\begin{array}{c}82(77-88) \\
72(68-76) \\
74(61-88) \\
0.003 \\
76(74-78) \\
0.07 \\
\end{array}$ & $\begin{array}{c}9(6-14) \\
20(17-23) \\
16(7-28) \\
0.0001 \\
15(14-17) \\
0.09 \\
\end{array}$ & $\begin{array}{c}8(3-18) \\
8(3-18) \\
10(3-20) \\
0.63 \\
8(7-10) \\
0.73 \\
\end{array}$ & $\begin{array}{c}86(81-91) \\
76(72-80) \\
79(67-91) \\
0.03 \\
79(77-81) \\
0.29 \\
\end{array}$ \\
\hline $\begin{array}{l}\text { FAB } \\
\text { classification }\end{array}$ & $\begin{array}{l}\text { M3 } \\
\text { M1-5 } \\
\text { M067 } \\
\text { P-value }\end{array}$ & $\begin{array}{c}80(75-85) \\
77(75-79) \\
53(42-64) \\
<0.0001 \\
\end{array}$ & $\begin{array}{c}11(7-15) \\
15(14-17) \\
33(24-43) \\
<0.0001\end{array}$ & $\begin{array}{c}9(5-16) \\
8(4-14) \\
14(8-21) \\
0.08 \\
\end{array}$ & $\begin{array}{c}85(80-89) \\
80(78-82) \\
63(53-73) \\
<0.0001 \\
\end{array}$ \\
\hline Year of autoSCT & $\begin{array}{l}1990-99 \\
2000-2008 \\
\text { P-value }\end{array}$ & $\begin{array}{c}78(76-80) \\
70(66-75) \\
<0.0001\end{array}$ & $\begin{array}{c}14(12-16) \\
19(16-23) \\
0.0003\end{array}$ & $\begin{array}{c}8(7-9) \\
10(8-11) \\
0.29\end{array}$ & $\begin{array}{c}81(79-83) \\
75(71-79) \\
0.0002\end{array}$ \\
\hline Status at autosCT & $\begin{array}{l}\text { CR1 } \\
\text { CR2 } \\
\text { P-value }\end{array}$ & $\begin{array}{c}76(74-78) \\
74(69-79) \\
0.37 \\
\end{array}$ & $\begin{array}{c}16(14-17) \\
18(14-22) \\
0.32 \\
\end{array}$ & $\begin{array}{c}8(7-10) \\
8(7-10) \\
0.98\end{array}$ & $\begin{array}{c}79(78-81) \\
77(72-82) \\
0.22\end{array}$ \\
\hline $\begin{array}{l}\text { Source of } \\
\text { stem cells }\end{array}$ & $\begin{array}{l}\text { BM } \\
\text { PB } \\
\text { P-value }\end{array}$ & $\begin{array}{c}80(77-83) \\
73(71-76) \\
<0.0001\end{array}$ & $\begin{array}{c}13(11-15) \\
18(16-20) \\
<0.0001\end{array}$ & $\begin{array}{c}7(6-9) \\
9(7-11) \\
0.09\end{array}$ & $\begin{array}{c}83(80-85) \\
77(75-79) \\
<0.0001\end{array}$ \\
\hline Graft purging & $\begin{array}{l}\text { No } \\
\text { Yes } \\
\text { P-value }\end{array}$ & $\begin{array}{c}75(73-77) \\
85(79-90) \\
0.004\end{array}$ & $\begin{array}{c}16(15-18) \\
11(7-16) \\
0.053\end{array}$ & $\begin{array}{c}8(7-10) \\
4(3-5) \\
0.04\end{array}$ & $\begin{array}{c}79(77-81) \\
86(81-92) \\
0.006\end{array}$ \\
\hline $\begin{array}{l}\text { TBI-based } \\
\text { conditioning }\end{array}$ & $\begin{array}{l}\text { No } \\
\text { Yes } \\
\text { P-value }\end{array}$ & $\begin{array}{c}76(74-78) \\
75(72-79) \\
0.65\end{array}$ & $\begin{array}{c}16(14-18) \\
16(13-19) \\
0.87\end{array}$ & $\begin{array}{c}8(7-10) \\
8(7-10) \\
0.7\end{array}$ & $\begin{array}{c}80(78-82) \\
77(73-81) \\
0.55\end{array}$ \\
\hline
\end{tabular}

Abbreviations: LFS - leukemia-free survival; RI - relapse incidence; NRM - non-relapse mortality; OS - overall survival, auto-SCT - autologous stem cell transplantation; FAB - French-American-British classification; CR1 first complete remission; CR2 - second complete remission; BM - bone marrow; PB - peripheral blood; TBI total body irradiation 
Table 3. Multivariate analyses

\begin{tabular}{|c|c|c|c|c|c|}
\hline & & $P$-value & Hazard & & \\
\hline & & & ratio & lower & upper \\
\hline LFS & $\begin{array}{l}\text { Patient age } \\
<50 \text { y (reference) }\end{array}$ & & 1 & & \\
\hline & $50-60$ & $<0.001$ & 1.89 & 1.59 & 2.24 \\
\hline & $>=60$ & $<0.001$ & 2.47 & 1.95 & 3.13 \\
\hline & CR2 vs CR1 & 0.03 & 0.30 & 1.03 & 0.64 \\
\hline & PB vs BM & 0.003 & 0.32 & 1.10 & 1.58 \\
\hline & FAB classification & & & & \\
\hline & M3 (reference) & & 1 & & \\
\hline & M1, M2, M4 or M5 vs M3 & 0.10 & 1.28 & 0.95 & 0.74 \\
\hline & M0, M6 or M7 vs M3 & $<0.001$ & 3.01 & 2.06 & 4.41 \\
\hline $\mathrm{RI}$ & $\begin{array}{l}\text { Patient age } \\
<50 \text { y (reference) }\end{array}$ & & 1 & & \\
\hline & $50-60$ & $<0.001$ & 1.60 & 1.30 & 1.98 \\
\hline & $>=60$ & $<0.001$ & 2.28 & 1.72 & 3.02 \\
\hline & CR2 vs CR1 & 0.02 & 1.42 & 1.07 & 1.89 \\
\hline & PB vs BM & 0.001 & 1.45 & 1.16 & 1.81 \\
\hline & FAB classification & & & & \\
\hline & M3 (reference) & & & & \\
\hline & M1, M2, M4 or M5 vs M3 & 0.01 & 1.72 & 1.14 & 2.59 \\
\hline & M0, M6 or M7 vs M3 & $<0.001$ & 4.39 & 2.69 & 7.18 \\
\hline NRM & $\begin{array}{l}\text { Patient age } \\
<50 \text { y (reference) }\end{array}$ & & 1 & & \\
\hline & $50-60$ & $<0.001$ & 2.58 & 1.87 & 3.56 \\
\hline & $>=60$ & $<0.001$ & 2.67 & 1.66 & 4.30 \\
\hline & Graft purging & 0.09 & 0.56 & 0.28 & 1.1 \\
\hline & FAB classification & & & & \\
\hline & M3 (reference) & & 1 & & \\
\hline & M1, M2, M4 or M5 vs M3 & 0.16 & 0.72 & 0.46 & 1.14 \\
\hline & M0, M6 or M7 vs M3 & 0.22 & 1.53 & 0.78 & 3.03 \\
\hline OS & $<50$ y (reference) & & 1 & & \\
\hline & $50-60$ & $<0.001$ & 2.07 & 1.70 & 2.51 \\
\hline & $>=60$ & $<0.001$ & 2.75 & 2.10 & 3.60 \\
\hline & CR2 vs CR1 & 0.02 & 1.35 & 1.05 & 1.75 \\
\hline & PB vs BM & 0.03 & 1.26 & 1.03 & 1.55 \\
\hline & FAB classification & & & & \\
\hline & M3 (reference) & & 1 & & \\
\hline & M1, M2, M4 or M5 vs M3 & 0.18 & 1.26 & 0.90 & 1.77 \\
\hline & M0, M6 or M7 vs M3 & $<0.001$ & 2.75 & 1.79 & 4.22 \\
\hline & TBI-based conditioning & 0.04 & 1.25 & 1.02 & 1.53 \\
\hline
\end{tabular}


1

2

3

4

5

6

7

8

9

10

11

12

13

14

15

16

17

18

19

20

21

22

23

24

25

26

27

28

29

30

31

32

33

34

35

36

37

38

39

40

41

42

43

44

45

46

47

48

49

50

51

52

53

54

55

56

57

58

59

60

Abbreviations: LFS - leukemia-free survival; RI - relapse incidence; NRM - non-relapse mortality; OS - overall

Survival, CI - confidence interval; BM - bone marrow; PB - peripheral blood; FAB - French-American-British classification; TBI - total body irradiation 


1
2
3
4
5
6
7
8
9
10
11
12
13
14
15
16
17
18
19
20
21
22
23
24
25
26
27
28
29
30
31
32
33
34
35
36
37
38
39
40
41
42
43
44
45
46
47
48
49
50
51
52
53
54
55
56
57
58
60

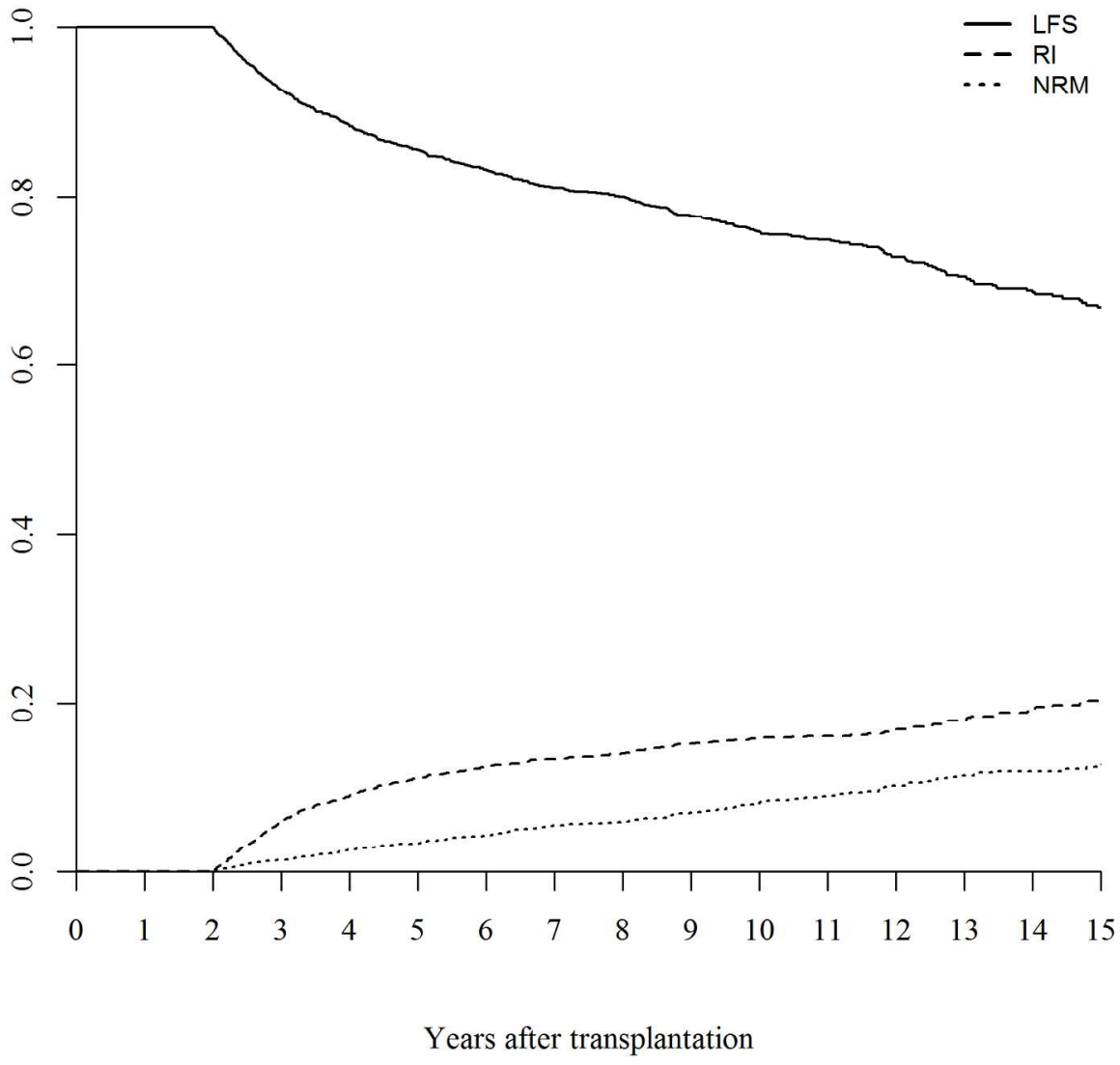

Figure 1

$169 \times 169 \mathrm{~mm}(300 \times 300 \mathrm{DPI})$ 


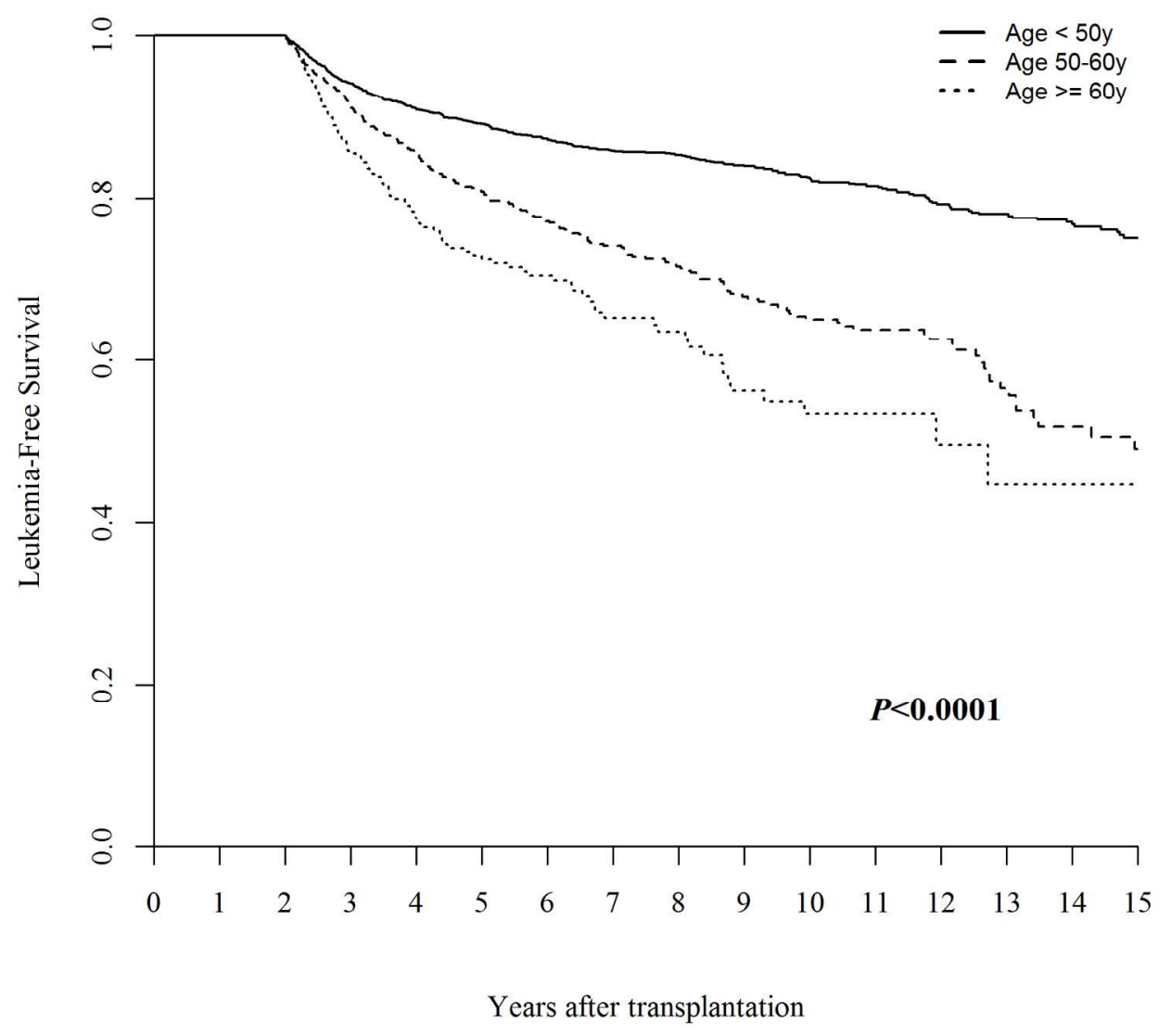

Figure 2.

$169 \times 169 \mathrm{~mm}$ (300 x 300 DPI) 


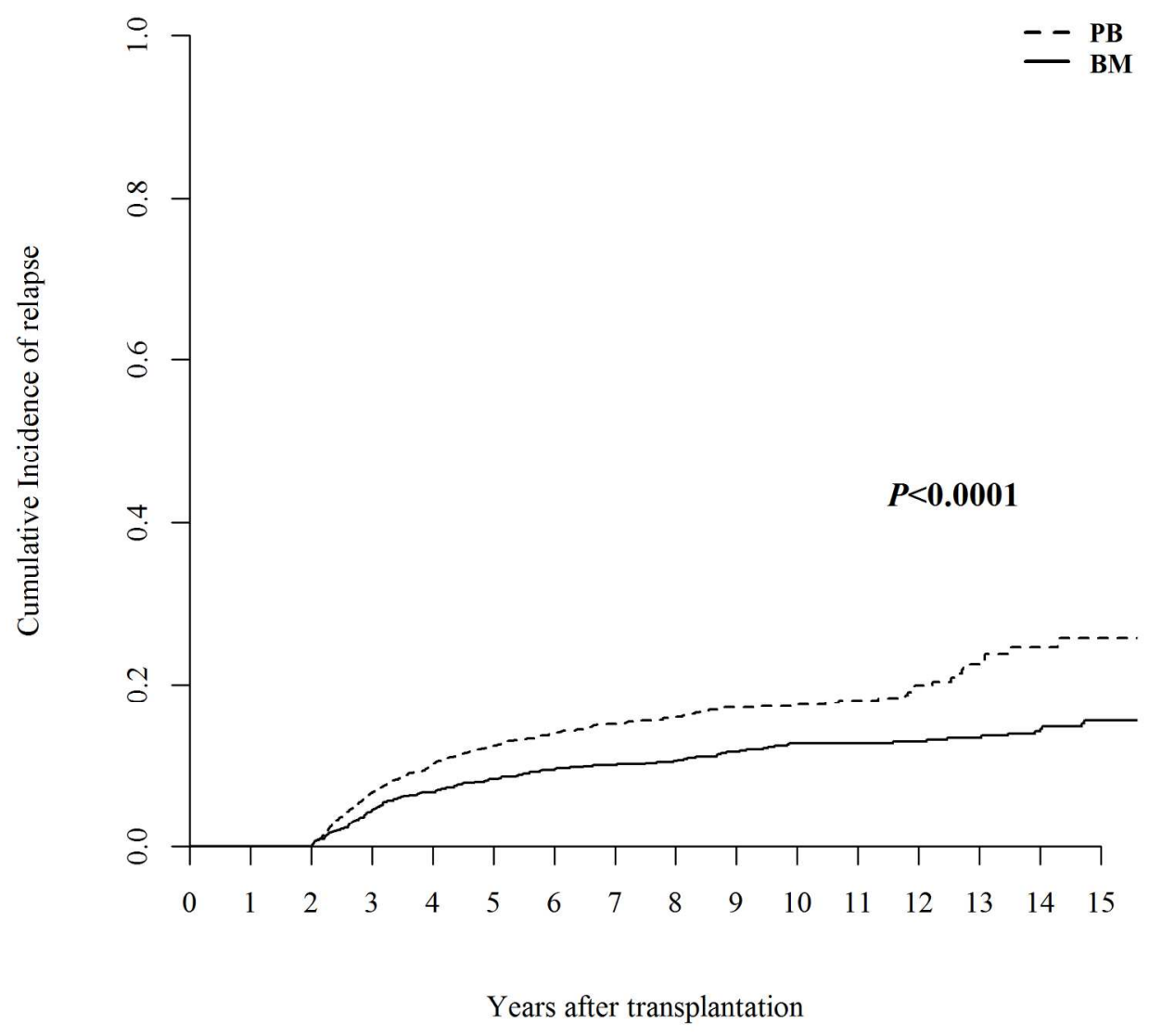

Figure 3

$354 \times 354 \mathrm{~mm}$ ( $144 \times 144$ DPI) 


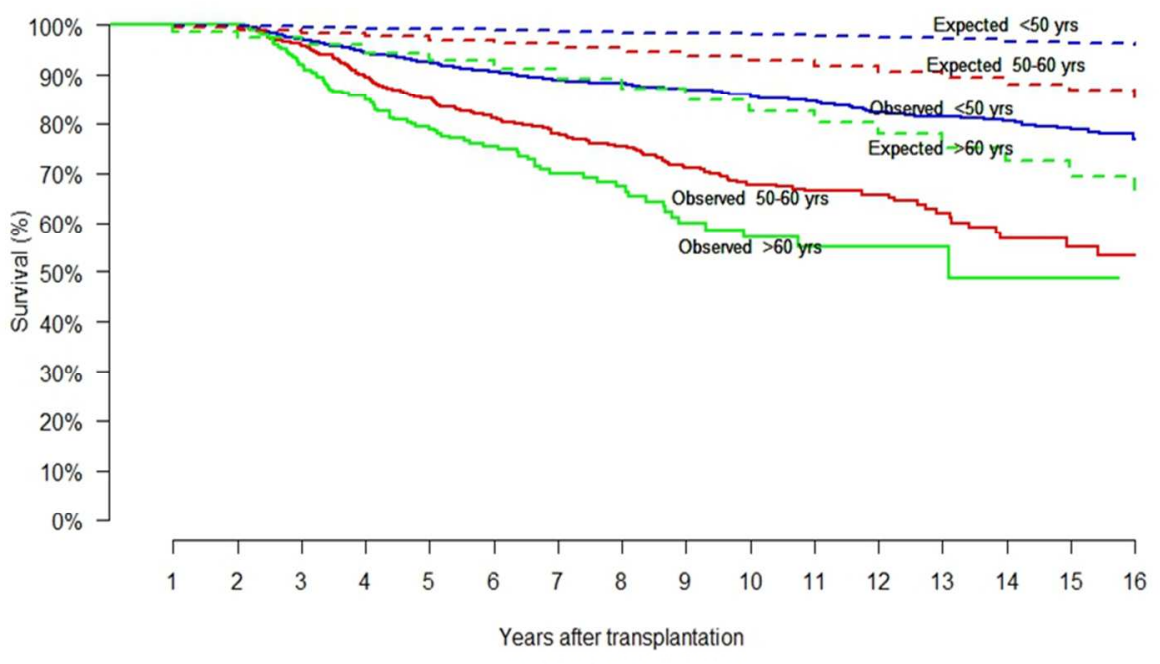

Figure 4.

$254 \times 190 \mathrm{~mm}(96 \times 96 \mathrm{DPI})$ 